Article

\title{
Drone Monitoring of Breeding Waterbird Populations: The Case of the Glossy Ibis
}

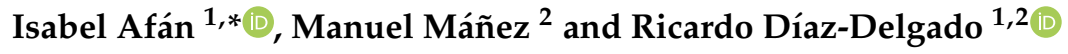 \\ 1 Remote Sensing and GIS Laboratory, Estación Biológica de Doñana (CSIC), 41092 Seville, Spain; \\ rdiaz@ebd.csic.es \\ 2 Natural Processes Monitoring Team, ICTS-RBD, Estación Biológica de Doñana, CSIC, 41092 Seville, Spain; \\ mmanez@ebd.csic.es \\ * Correspondence: isabelafan@ebd.csic.es; Tel.: +34-954-466700
}

Received: 1 November 2018; Accepted: 27 November 2018; Published: 1 December 2018

\begin{abstract}
Waterbird communities are potential indicators of ecological changes in threatened wetland ecosystems and consequently, a potential object of ecological monitoring programs. Waterbirds often breed in largely inaccessible colonies in flooded habitats, so unmanned aerial vehicle (UAV) surveys provide a robust method for estimating their breeding population size. Counts of breeding pairs might be carried out by manual and automated detection routines. In this study we surveyed the main breeding colony of Glossy ibis (Plegadis falcinellus) at the Doñana National Park. We obtained a high resolution image, in which the number and location of nests were determined manually through visual interpretation by an expert. We also suggest a standardized methodology for nest counts that would be repeatable across time for long-term monitoring censuses, through a supervised classification based primarily on the spectral properties of the image and a subsequent automatic size and form based count. Although manual and automatic count were largely similar in the total number of nests, accuracy between both methodologies was only $46.37 \%$, with higher variability in shallow areas free of emergent vegetation than in areas dominated by tall macrophytes. We discuss the potential challenges for automatic counts in highly complex images.
\end{abstract}

Keywords: UAV; aerial survey; long-term monitoring; Plegadis falcinellus; bird censuses; supervised classification; image processing

\section{Introduction}

Ecological monitoring programs are fundamentally important for maintaining long-term series of data to evaluate the impact of anthropogenic activities and global change on protected areas [1-3]. Most conservation policies and management decisions rely primarily on information from monitoring programmes that focus on the ecosystem structures and processes and biodiversity variables as species populations [4-6]. One of the main goals of population monitoring programs is the study of species distribution changes over time. In this regard, it is crucial to develop consistent methods to monitor species distribution and abundance that will allow us to assess measures of population fluctuations [7].

Birds can be excellent barometers of environmental health [8], particularly in threatened habitats as wetlands, where both species trophic resources and breeding conditions largely depend on ecological and hydrological conditions. Accordingly, waterbird communities are extremely sensitive to changes in the availability of suitable wetland habitats, becoming indicator species to promote conservation awareness and actions [9]. However, as most species of waterbirds breed in largely inaccessible colonies within flooded habitats, it is difficult to carry out surveys of colonial wetland birds in situ. Many of these bird species breed densely aggregated in inaccessible places with no possibility of performing ground surveys without causing serious disturbances to the breeding individuals [10]. Furthermore, 
the breeding places often contain several species breeding in sympatry. Consequently, aerial surveys have become one of the most common methods for censusing colonies of waterbirds [11-14]. One of the main constraints of this methodology is the limited spatial resolution resulting from aircrafts flights, often not suited to local-scale ecological investigations [15]. Therefore, the application of UAVs has been a qualitative leap in bird monitoring, enabling rapid, low disturbance surveys of inaccessible areas while delivering repeatable images with a fine spatial resolution [16-19].

Despite the fine spatial resolution data that UAVs can deliver, there is some bias inherent in this methodology that could hamper the extraction of accurate population data of densely colonial aggregations of birds: the absence of ground-truth data in inaccessible habitats, the difficulty of isolating and quantifying individuals or nests because of their cryptic nature or poor visibility through the canopy [11] and the potential negative interactions between bird and drones [20,21]. Furthermore, the quality of sensors is rapidly increasing, resulting in progressively very large images which are difficult to treat with standard image processing software. Based on historical aerial surveys of waterbirds, counting error has proved to be one of the most serious problems for aerial surveys [14]. Individuals or nest counts have primarily relied on manual interpretation of the images produced. This can be time-consuming if imagery is collected over large areas and dense congregations of birds [22]. Thus, the use of both manual and automated detection routines for features counting and the development of automatic tools to detect large numbers of birds automatically from images has become a necessary subject matter for current research [21-23].

This study was developed on Doñana National Park (SW Spain), one of the largest protected wetlands in Europe with a typical Mediterranean climate. Doñana holds a large extent of temporary marshes $\left(340 \mathrm{~km}^{2}\right)$. Wetland flooding patterns fluctuate interannual and seasonally, with natural climatic variability or anthropic modifications, modifying substantially the suitable area for breeding species [24]. Doñana is also recognized as a Long-Term Socio-Ecological Research (LTSER) platform integrated in the LTER-Europe network [25] by applying harmonized protocols for long-term socio-ecological research. We particularly focus on observations of a colonial species, the Glossy ibis Plegadis falcinellus, a species nesting in Doñana [26] where it has undergone an explosive population expansion from seven pairs in 1996 to more than 10,000 pairs by 2017 [27-30]. Glossy ibis is considered as least concern status by the International Union for the Conservation of Nature (IUCN) by its extremely large distribution range [31], but is cited as a conservation concern in the Spanish Red Data Book [32]. However, the species is threatened by wetland habitat degradation and loss [29,33], so their surveillance has a high priority within the long-term monitoring programs of Doñana National Park. Furthermore, the number of breeding pairs has increased dramatically in recent years in the FAO colony, with a total population in Doñana wetlands exceeding 10,000 pairs in 2017 [30]. This, combined with the fact that the species breeds in marshes, with nests positioned less than one meter above water in tall dense stands of emergent vegetation [29], makes ground censuses totally out of reach. The cryptic nature and dark colours of this species represent also a challenge for their discrimination by way of aerial censuses.

The purpose of this study was to evaluate the capabilities of UAVs to perform aerial censuses of densely populated wetland colonies of waterbirds, with the aim of integrating unmanned aerial flights in the long-term monitoring bird populations censuses. Our particular objective was to estimate the number of breeding pairs of Glossy ibis in the study area, comparing the capability of manual and automatic count procedures based on image-analysis techniques that use the spectral, size and form characteristics of the target species for an automatic recognition [14,23]. The final objective is to evaluate whether UAV surveys can be integrated as an efficient and standardized tool for long-term monitoring of colonial breeding waterbirds in Doñana National Park. 


\section{Materials and Methods}

\subsection{Species and Study Area}

The first breeding report for Glossy Ibis at Doñana wetlands dates back to 1770 [34], but the species was pushed to extinction by hunting and the pillaging of the eggs during the early years of the twentieth century. It was not until 1996 that the species became re-established and bred regularly in Doñana. This natural area contained $90 \%$ of the Spanish breeding population of Glossy ibis in 2001 [29]. At present, "Lucio de la FAO" hosts the main Glossy ibis colony at Doñana National Park, a large mixed colony where it breeds in association with other species, regularly Ardeidae (Figure 1a).

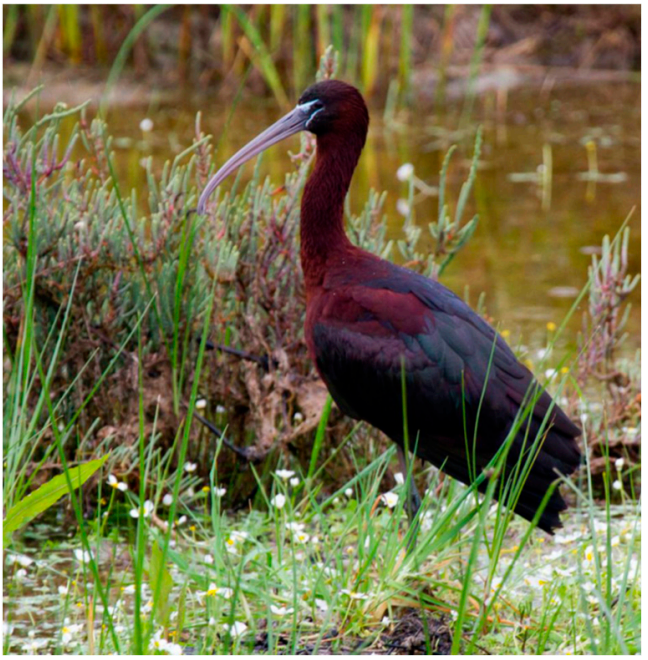

(a)

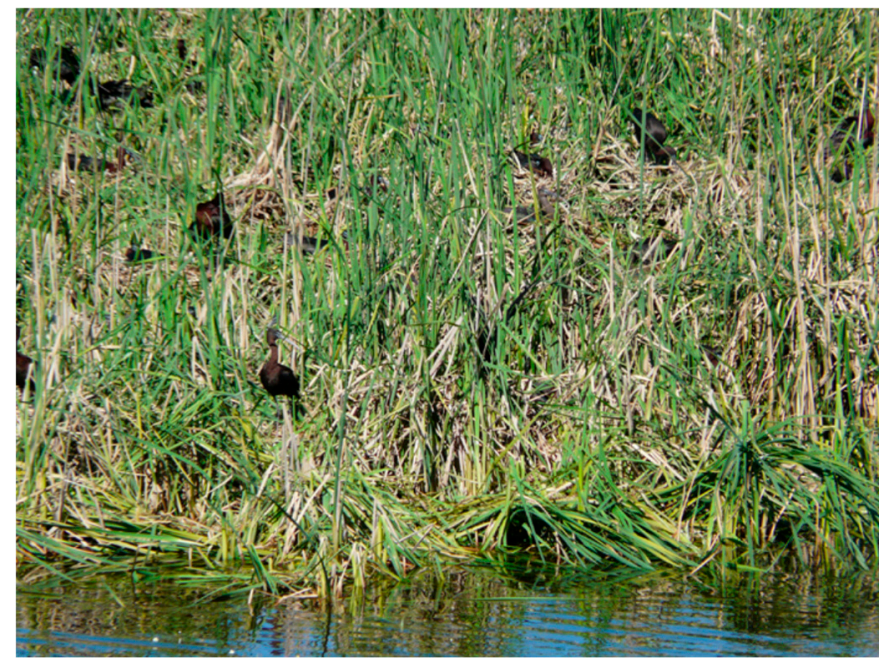

(b)

Figure 1. (a) Glossy ibis (Plegadis falcinellus) individual. (b) Front view of the Glossy ibis colony, densely covered by the macrophyte Typha, which makes it extremely difficult the ground census of the colony. Photos: Carlos Gutiérrez-Expósito (a), and Manuel Máñez (b).

The "Lucio de la FAO" is a system of three interconnected semi-artificial ponds covering a total surface area of about 50 ha which is flooded by both direct precipitation and groundwater pumped from the underlying aquifer. The vegetation cover varies with locally dense stands of Typha (mostly used for nesting, Figure 1b), areas dominated by tall Tamarix scrub and shallow areas free of emergent vegetation [26].

\subsection{Drone Survey Method}

One aerial survey was conducted over the main breeding colony of Glossy ibis in Doñana National Park (37 $4^{\prime} 23^{\prime \prime} \mathrm{N}, 6^{\circ} 2^{\prime} 46^{\prime \prime} \mathrm{W}$, Figure 2a,b) on 14 May 2018 between 10:00 and 10:33 hours (local time). The survey was done using a Phantom 4 Pro quadcopter (DJI Innovations, Shenzhen, China). This UAV was equipped with a compact $4 \mathrm{~K}$ digital camera of 20 megapixels ( $24 \mathrm{~mm}$ lens). The exposure time was set automatically using "speed priority" mode. The Phantom UAV was remotely controlled with a handheld unit keeping the legal maximum distance of $500 \mathrm{~m}$ from the operator. 


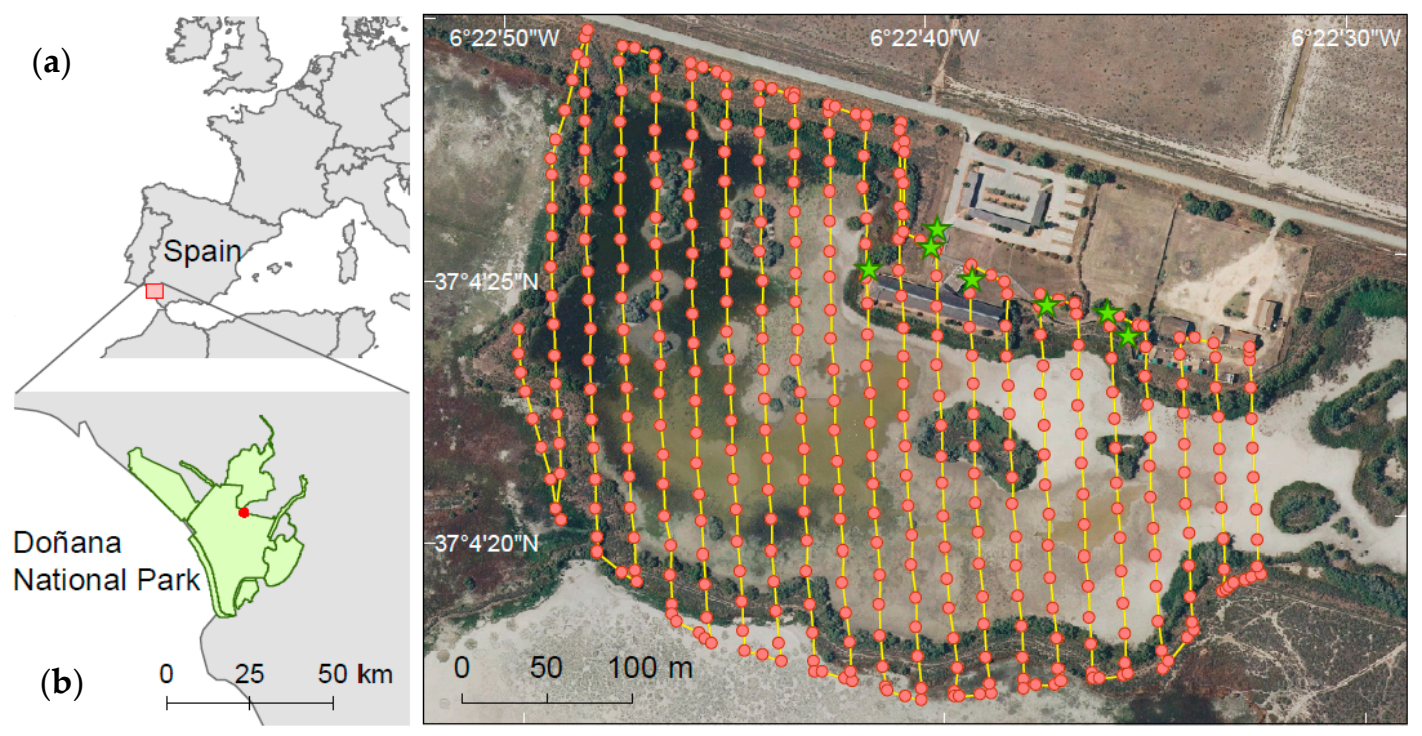

(c)

Figure 2. Location of Doñana National Park, SW Spain $(\mathbf{a}, \mathbf{b})$. Red dots indicate the situation of the Glossy ibis colony. (c) Automatic flight path covered by the UAV to collect image of the Glossy ibis colony in "Lucio de la FAO". The UAV followed 22 predefined transect lines (yellow lines, $6292.2 \mathrm{~m}$ ) with $80 \%$ front overlap and $70 \%$ side overlap. Green stars show ground control points (GCPs) established to increase the absolute global accuracy of drone image.

The UAV followed an automatic flight programmed beforehand with 22 transect lines covering an area of 16.1 ha with $80 \%$ front overlap and $70 \%$ side overlap (see Figure $2 \mathrm{c}$ ). The flight settings were defined using Pix4DCapture mobile app (Pix4D SA). The drone was flown at an altitude of $50 \mathrm{~m}$ above ground elevation and at a ground speed of $12 \mathrm{~km} \mathrm{~h}^{-1}$ (Figure 3a,b). A total of 448 images were taken. The ground sample distance (GSD), being the distance between adjacent pixel centres on the ground was $0.0132 \mathrm{~m}$. Environmental conditions provide optimal flight conditions: high visibility (>1000 m), no cloud cover and wind speeds $<4 \mathrm{~m} \mathrm{~s}^{-1}$. The total duration of the census was ca. $1 \mathrm{~h}$. No adverse behaviours from birds against the UAV or disturbance reactions were observed.

Flight was operated during the late hatching period of the Glossy ibis, to assure that only one individual from the breeding pair was lying on the nest, while the other fed in the nearby foraging marshland areas. Both sexes of Glossy ibis individuals alternate to incubate the eggs and feed the chicks [35], and the exchange takes place early in, and at the end of the day, with no interference during the flight time.

The pictures were mosaicked with the Pix4Dmapper photogrammetric software (Pix4D SA, Switzerland) to obtain a single multiband RGB image of the colony. The Pix4D computing consists of three steps: initial processing, point cloud densification and DSM and orthomosaic generation, which are carried out automatically [36]. The final spatial resolution of the orthomosaic was $0.0132 \mathrm{~m}$. Only seven ground control points (GCPs) could be placed using conspicuous elements in the accessible area (see in Figure 2 the paths surrounding the main building) providing a mean RMS (root mean square error) of $0.06 \mathrm{~m}$. 

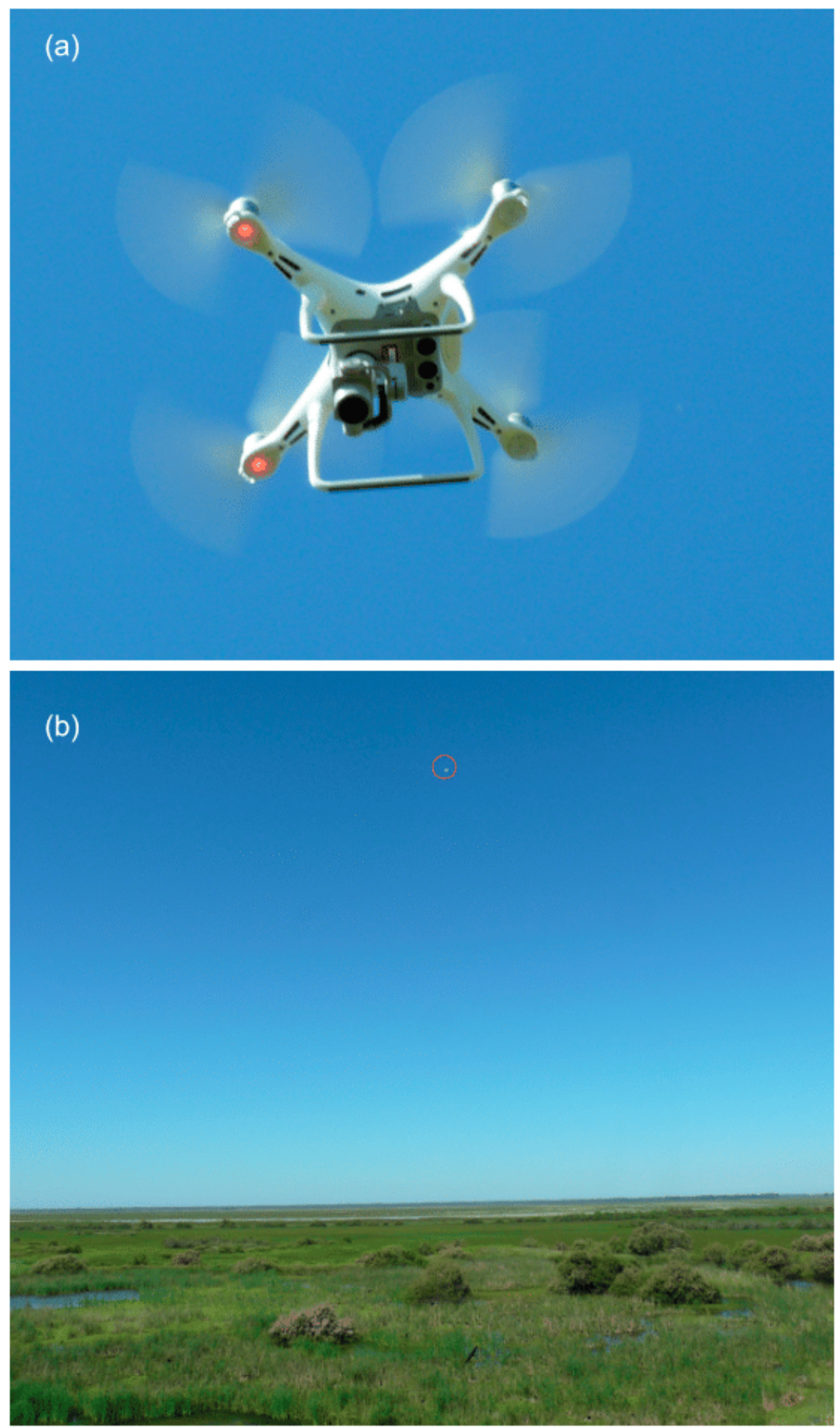

Figure 3. (a) Drone used to survey the Glossy ibis colony, Phantom 4 Pro quadcopter. (b) Phantom 4 surveying the colony at $50 \mathrm{~m}$ of altitude. Birds show no disturbance. Photos: Manuel Máñez.

\subsection{Visual Identification of Breeding Birds}

Confronted with an inability to collect ground-truth data for several of the nesting birds in the colony, we performed a manual and visual identification of the breeding birds in the orthomosaic. An experienced ornithologist identified birds sitting on nests 'by eye'. A point vector file with nest positions was created while onscreen digitizing at 1:30 scale. Other sympatric breeding species, 
whenever visible, were also geolocated in the image. Visual identification was performed in ArcGIS 10.5 (ESRI, Redlands, California, U.S.A.).

\subsection{Automatic Identification of Breeding Birds}

The automatic detection of breeding individuals was accomplished in two steps: first we performed a supervised classification based primarily on the spectral properties of the image with the aim of simplifying the original complexity of the entire scene and enhancing the subsequent automatic detection of Glossy ibis individuals. In a second stage, we carried out an automatic count using image processing software where size and form were introduced to the recognition process.

\subsubsection{Supervised Classification}

A supervised classification segments the spectral domain of an image and assigns every pixel a probability of belonging to one of the classes of interest, based on the spectral information of homogeneous training areas for the different thematic classes being considered [37]. We used a Random Forest supervised classification to classify the original image into three classes. The Random Forest classifier consists of a combination of decision trees from randomly selected subset of a training set. The trees are created by drawing a subset of training samples through replacement: two-thirds of the data are sampled for training and the remaining third of the data are excluded for validation. The final classification decision is taken by averaging the class assignment probabilities calculated by all produced trees. A new unlabelled data input is thus evaluated against all decision trees created in the ensemble and each tree votes for a class membership. Pixels are classified by taking the most popular voted class from all the tree predictors in the forest [38,39]. Random Forests are widely popular because of their ability to classify large amounts of data with high accuracy and preventing overfitting [39]. We used breeding birds sitting on their nests from the orthomosaic as training areas for the class "ibis". Nest structures, typically completely covered by guano, represent the second class. The third class evaluated comprised areas covered by a homogenous film of Lemna. The remaining more complex vegetation and other species (i.e., Purple heron) were not considered because those classes shares spectral properties with the Glossy ibis and their inclusion considerably reduced the accuracy of classification. A total of 33,977 pixels were selected for the training features, with a similar number of pixels for the three classes (class balanced). A total of 100 trees were used. The resulting image was reclassified to maintain only the category "ibis".

All analyses were conducted in R [40]. The packages rgdal [41], raster [42], caret [43], and randomForest [44] were also used.

\subsubsection{Image Processing}

Image analyses were performed with the freely available Fiji distribution of Image software (developed at the US National Institutes of Health) [45,46] and the "Analyse Particles" function which counts objects in binary or thresholded images. Supervised classification and subsequent reclassification through a binary image was used as input for the image analysis. This step avoids the need to select a threshold value which will prevent objects above a certain pixel value being included in the automatic count total.

One hundred Glossy ibis individuals randomly distributed in the study area were digitalized with a $600 \times$ zoom. Size and form (circularity) measures were extracted to determine the upper and lower threshold limiting size and form-based selection of particles to be counted. The resulting grid classified image showing the detected particles was vectorized in ArcGIS 10.2 (ESRI, Redlands, California, U.S.A.)., applying first a low pass filter and a majority filter to soften the limits of the areas classified as ibis individuals. Micropolygons with a surface area of less than $0.007 \mathrm{~m}^{2}$, which had split from complex shaped polygons during the vectorization process, were removed. 


\subsection{Validation}

To test whether the automatic method was reliable, accuracy (proportion of nests mapped correctly), commission errors (proportion of nests counted automatically but left out in the manual process) and omission errors (proportion of nests omitted in the automatic procedure) were determined by spatial comparison of georeferenced nests obtained from the automatic process to those visually determined over the image by an expert. Validation was performed on the total colony and on six square sample plots of $329 \mathrm{~m}^{2}$, selected over the main vegetation types where nests were settled, as derived from visual inspection of the orthomosaic obtained: three sample plots in the flooded areas densely covered by macrophytes (mainly Typha, number of nests ranged 94-228) and three in the free areas of emergent vegetation but covered with a layer of aquatic plants (Lemna spp, number of nests ranged 126-161).

Spatial overlap was conducted between the individuals obtained from the vectorization of the automatic classified image and a buffer area of $0.15 \mathrm{~m}$ of radius around the nests detected manually. A visual inspection was also performed to assure that all identified nests were inside their corresponding overlap area.

Validation plots were also used for estimating Glossy ibis nest density and nest distance in each vegetation class from the manual georeferenced nests.

\section{Results}

The orthomosaic obtained from the aerial survey showed an area of 16 ha covering the complete surface of the Lucio de la FAO where Glossy ibis breeds (Figure 4). The Glossy ibis colony was based in a continuous area of 3.2 ha with two major classes of vegetation cover: flooded areas covered by macrophytes (mainly Typha) and free areas of emergent vegetation but covered with aquatic plants (Lemna spp). Regardless the vegetation type cover around the nests, Typha invariably constitute the predominant nesting material (Figure 4a). No nests were found over Tamarix shrubs.
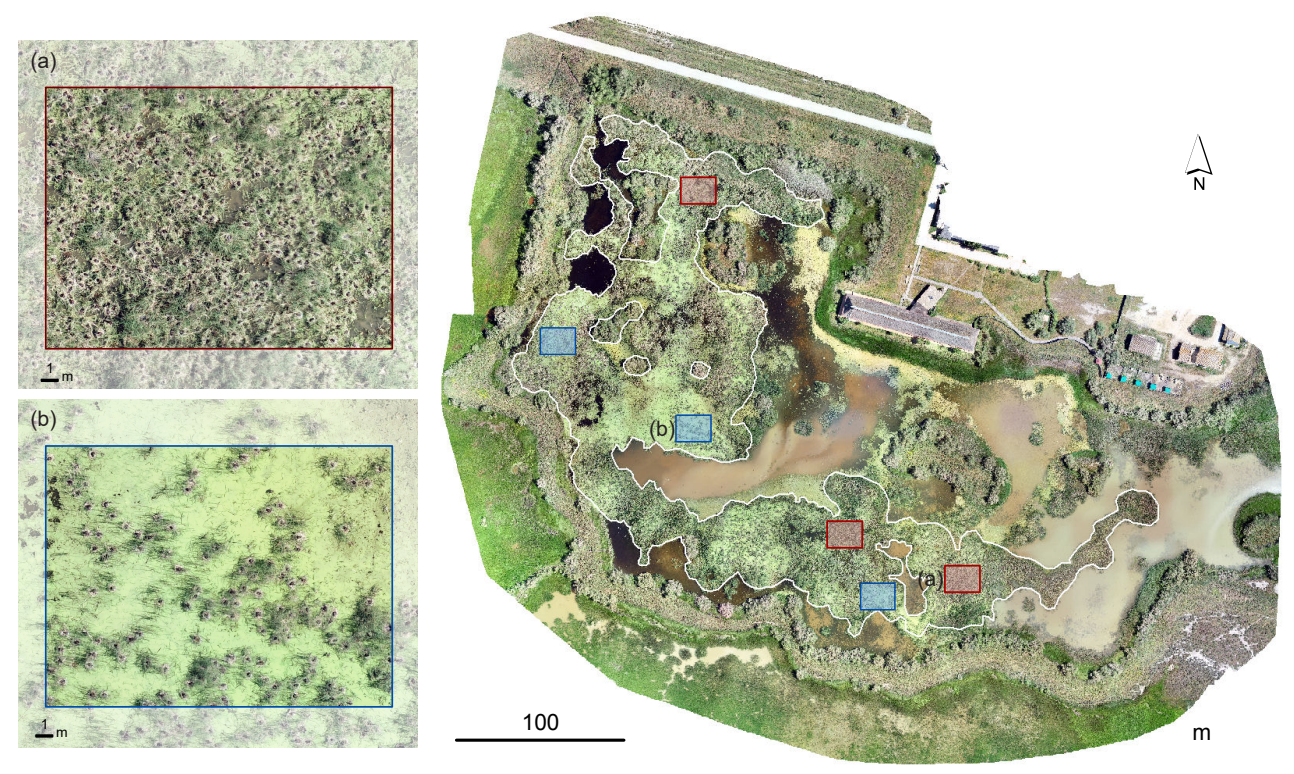

Figure 4. Orthomosaic image of high-resolution of the Glossy ibis colony in "Lucio de la FAO". Image was mosaicked with Pix4D mapper Pro (Pix4D, Switzerland) after acquiring 448 photos through automatic flight of Phantom 4 Pro quadcopter (DJI Innovations, Shenzhen, China) on 14 May 2018. Squares show validation areas to test the accuracy of the automatic nest counting method to the visually nest count by an expert. Blue squares show densely macrophytes area (Typha spp) whereas red squares showfree areas of emergent vegetation covered by Lemna aquatic plant. White line delineates the Glossy ibis nesting area. 


\subsection{Manual Counting}

Visual identification of lying birds on nest identified a total of 7134 individuals of Glossy ibis together with 439 individuals of Purple heron (Ardea purpurea). Glossy ibis nests measured $0.57 \pm 0.1 \mathrm{~m}$ (mean \pm SD) in diameter $(n=50)$, similar to those of Purple heron $(0.70 \pm 0.24, n=50)$. Glossy ibis nests were densely distributed throughout the colony $\left(0.22\right.$ nests $\left.\mathrm{m}^{-2}\right)$, with similar density in areas covered by different vegetation classes, as Typha or Lemna areas ( 0.4 nests $\mathrm{m}^{-2}$, Table 1$)$. Minimum proximity distance within nests was lower than $0.5 \mathrm{~m}$ in all areas, with maximum proximity distances up to $7 \mathrm{~m}$ (Table 1). Purple heron nests were not uniformly distributed into the Glossy ibis breeding area, with a preference for areas with greater vegetation cover of Typha.

Table 1. Glossy ibis nest density, minimum nest distances (mean $\pm \mathrm{SD}$ and range) obtained from manual georeferencing of nests, in the total colony and inside the three validation areas selected for each vegetation class. The number of total Glossy ibis nests and range number of nests considered for each vegetation class is also shown.

\begin{tabular}{|c|c|c|c|c|}
\hline Area & $\begin{array}{l}\text { Nest Density } \\
\left(\text { Nests } \mathrm{m}^{-2}\right)\end{array}$ & $\begin{array}{l}\text { Nest Distance } \\
\text { (m) }\end{array}$ & $\begin{array}{l}\text { Nest Distance } \\
\text { (Range, m) }\end{array}$ & $\begin{array}{c}\text { Number of } \\
\text { Nests }\end{array}$ \\
\hline Total colony & 0.22 & $0.88 \pm 0.48$ & $0.26-7.84$ & 7134 \\
\hline Typha spp. & $0.41 \pm 0.22$ & $0.82 \pm 0.36$ & $0.32-3.85$ & $94-228$ \\
\hline Lemna spp. & $0.43 \pm 0.05$ & $0.79 \pm 0.42$ & $0.33-3.35$ & $128-161$ \\
\hline
\end{tabular}

\subsection{Automatic Counting}

The automatic bird count showed a total of 8,060 nesting birds, but was unable to distinguish between the two species breeding in the colony (Figure 5). Total accuracy between nest counts manually and nests counted by the automatic procedure was of $43.65 \%$. Accuracy was similar in areas with dense canopy covered by macrophytes (Typha) (50.37\%, Table 2), than in open areas only covered by Lemna (49.01\%, Table 2). Nevertheless, variability between validation plots was much higher in Lemna than in Typha areas (Table 2).

Table 2. Accuracy (total agrees with the percent of total nests detected), commission, and omission errors obtained between manual count and automatic nest counting procedure, in the total colony and in average and SD for the three validation plots selected for each vegetation classes. The number of total Glossy ibis nests and range of nests enclosed in the three validation areas considered for each vegetation class is also shown.

\begin{tabular}{ccccc}
\hline Area & Accuracy (\%) & Commission Error (\%) & Omission Error (\%) & Number of Nests \\
\hline Total colony & 46.37 & 66.61 & 53.63 & 7134 \\
Typha spp. & $50.37 \pm 2.19$ & $55.06 \pm 27.79$ & $49.63 \pm 2.19$ & $94-228$ \\
Lemna spp. & $49.01 \pm 19.22$ & $22.64 \pm 7.45$ & $50.99 \pm 19.22$ & $128-161$ \\
\hline
\end{tabular}



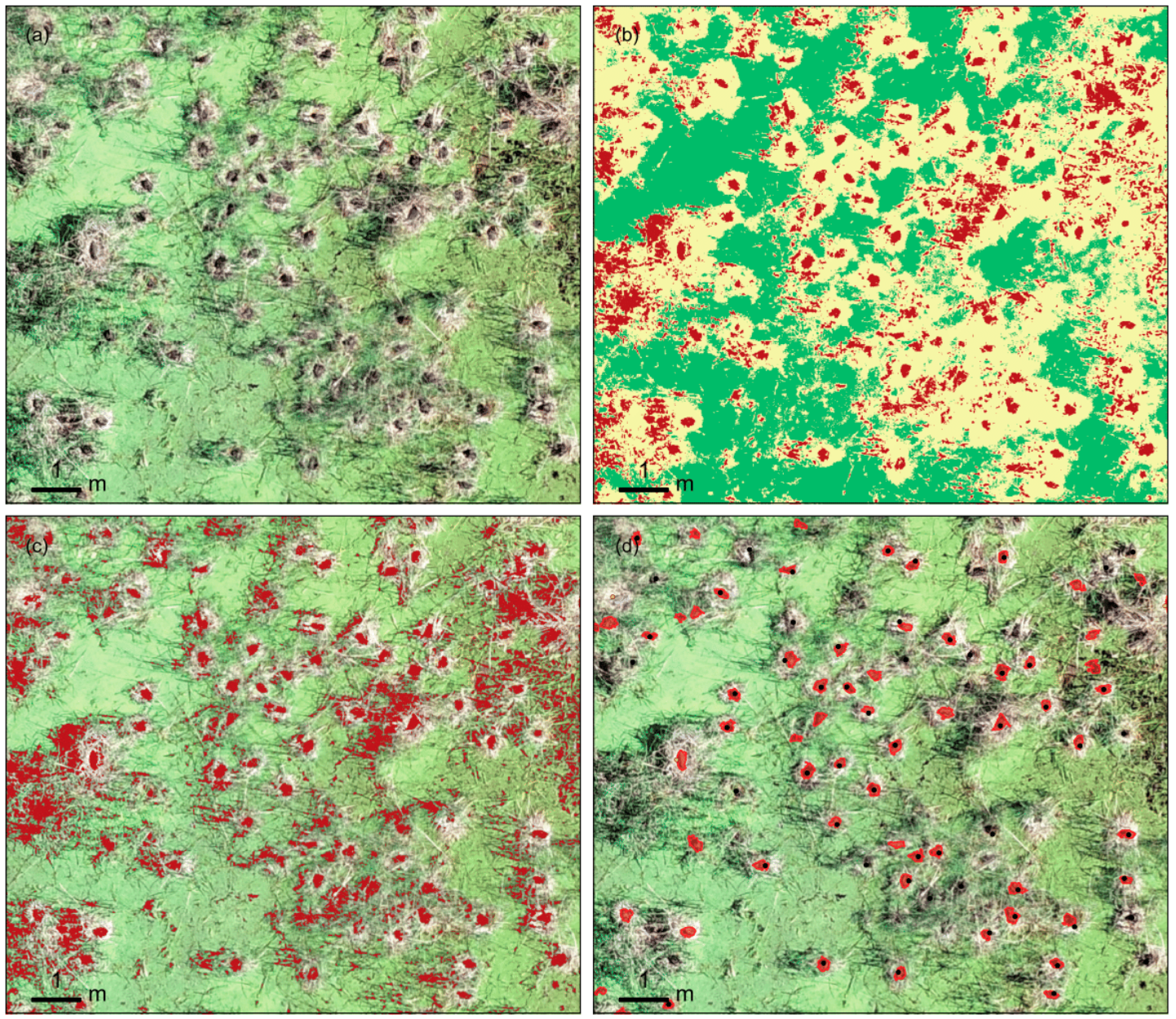

Figure 5. Automatic Glossy ibis nests count process. (a) Overview of the Glossy ibis nests from the orthomosaic obtained by the UAV. (b) Result of the Random Forest supervised classification. Pixels were classified into three classes: Glossy ibis (red), nest structures (yellow) and Lemna cover (green). (c) Two-bits image, result of the reclassification of the supervised classified image to maintain only ibis class. (d) Glossy ibis laying individuals automatically obtained by the image processing software (ImageJ), size and form based. Dots show identified nests by visual inspection (black dots indicate Glossy ibis nests and yellow dot indicates Purple heron nest).

\section{Discussion}

The survey conducted by means of UAV technology, allowed us to obtain a high-resolution image of the main Glossy ibis colony in the Doñana National Park, settled in a flooded inaccessible area. From this orthomosaic, we determined the nests established, their spatial location and the presence of another species (Purple heron), albeit in a minority, breeding in sympatry with the Glossy ibis. The spatial resolution accomplished by the flight allowed a good by-eye estimation of the breeding population, since nest structures and Glossy ibis individuals were able to be identified in the orthomosaic. Despite this, the automatic count was less accurate than the manual count, with the automatic count consistently failing to detect the $50 \%$ of the birds in the image.

The census of Glossy ibis breeding in Lucio de la FAO was in fact a challenging task: this colony hosts a high density of individuals, nests are constructed inside macrophytic vegetation up to more than one meter in height, and the target species has a dark-coloured plumage, which makes it difficult to stand out from the background. Indeed, aerial censuses of this species had produced very poor outcomes, detecting only $17 \%$ of the nests in freshwater marshes [11]. Therefore, the accuracy rates in waterbird colony manual counts have clearly improved with the use of UAVs technology, allowing near $100 \%$ of nests recognition with image resolutions under $0.01 \mathrm{~m}$, and ideally when 
reached $0.005 \mathrm{~m}$ [10]. Dulava et al. [47] recommended an image resolution of $\sim 0.005 \mathrm{~m} /$ pixel to enable correct species identification [48]. Object-oriented approaches also recommend very high resolution images $(0.01 \mathrm{~m} /$ pixel or finer) [23]. With a spatial resolution of $0.01319 \mathrm{~m} /$ pixel obtained in our trial, performance shortcomings in automatic counts in this work can be likely attributed in part, to an insufficient image resolution. Furthermore, the automatic count omitted those individuals not well isolated from their background. Shaded vegetation and dark areas of water were assigned to the same group as dark Glossy ibis individuals in the course of the supervised classification process, causing commission errors during the counting process. On the other hand, white guano areas laid on the nest material, which were easily recognized throughout the classification, allowed a good isolation of breeding individuals. However, nests with a reduced white guano envelope were more likely to be omitted during the automatic count process. The automatic count performed similar at nest detection in canopied macrophytes areas (Typha spp) than in open waters covered by Lemna. However, variability in detection was much higher in Lemna areas. Low detection may be related to patches of dark water within the Lemna beds could be mistaken for the 'Ibis class' if they were within the size limit determined for Glossy Ibis particles.

While an improvement of the spatial and radiometric resolution of the image may provide a better outcome, we propose here a methodology that allows a standardized automatic nesting count, easily implementable and repeatable across time for long-term monitoring censuses. Reducing the complexity of images for extracting information usually relies on a thresholding step, which transforms the original image into a binary one, in which a cut-off value determines the level above and below which the pixels will be selected for being measured [49]. Consequently, this is one of the most critical and at the same time subjective steps in the image processing. Thresholding has proved to be highly effective in cases where target features are spatially separated and where they do not share the same spectral range as other image elements in the background [50-52]. However, in situations without high bird contrast, classifications can be considered as an alternative approach to isolate birds from background features [52-54]. With regard to the complexity of the Glossy ibis colony image, we have performed a supervised classification for simplifying the spectral classes of the original image and reduce the file size. Both processes were needed to enhance the capabilities of image processing software (ImageJ). In addition, size and shape filtering, particularly roundness, which has been proved to be effective detecting several bird species $[52,53]$ was subsequently used.

The results derived from this study demonstrate the capability of UAV censuses for detailed monitoring of Glossy ibis (and, therefore, other waterbirds breeding in similar habitats), and their applicability for obtaining long term comparable breeding population trends. For many waterbird populations, aerial surveys are proving the only way to collect data over large areas at a relatively low cost [14]. This case study reveals the benefits and limitations of the applicability of UAVs for waterbirds monitoring: drones are capable of collecting high-resolution spatial data in difficult access areas, with non-significant disturbance to the breeding birds, and with an affordable cost depending on the surface to be covered [16]. In this particular case, the colony could be flown over in a short time (one hour), which was helped by the proximity of access routes, which results in a suitable compromise between cost and results obtained. The extraordinary growth in recent years of the breeding population of this species means that any other methodology for obtaining breeding data is unfeasible. The Glossy ibis colony needs a low altitude flightfor providing images of sufficiently high resolution to accurately isolate individual nests in the image, but without causing disturbance to the breeding birds and their chicks. Indeed, the resolution accomplished to date allows a manual approach to counting nests, but is still unsatisfactory for an automatic estimate. As UAV capabilities will increase, in terms of flight endurance and sensor resolution, a larger amount of high-resolution data will be collected, and automatic processing will become a major need [55]. Adjusting automatic procedures is essential to incorporate UAV data into long-term monitoring programs, since this will reduce bias due to visual interpretation and provide comparable data over time. 
Author Contributions: Conceptualization, I.A., M.M. and R.D.-D.; Data curation, M.M. and R.D.-D.; Formal analysis, I.A., M.M. and R.D.-D.; Methodology, I.A., M.M. and R.D.-D.; Writing-original draft, I.A.; Writing—review \& editing, M.M. and R.D.-D.

Funding: Consejería de Medio Ambiente y Ordenación del Territorio of Junta de Andalucía and the ICTS program by the Spanish Ministry of Science and Technology provide funding for the Long Term Monitoring Program of Doñana Natural Space including drone flights. Waterbird surveys have been funded through a contract with Environment and Water Agency (AMAYA), of the Regional Environment Authority of Andalusia.

Acknowledgments: We thank to the Natural Processes Monitoring Team (Birds) from Estación Biológica de Doñana (currently formed by Luis García, José Luis del Valle, José Luis Arroyo, Rubén Rodríguez and Antonio Martínez) for all the effort to the collect of long monitoring data on Glossy ibis. We are very grateful to Clive Hurford for their constructive review and David Aragonés and Francisco Ramírez for helpful comments.

Conflicts of Interest: The authors declare no conflict of interest.

Statements: This study complied with Spanish legislation (Law 48/1960 and Reales Decretos 1036/2017, 552/2014, and 57/2002) defining regulation for civil use of Remotely Piloted Aircraft Systems (RPAS). EBD-CSIC is a legal listed operator by AESA since 2017 and as CSIC since 2015. Declared activities include research and development (https: / / www.seguridadaerea.gob.es/media/4305572/listado_operadores.pdf page 181). The radio frequency used for UAS radio control was $35 \mathrm{MHz}$, which is the frequency authorized for radio control for leisure applications in Europe under directive 1999/05/EC. The project had the permission of the National Park authorities on nature conservation.

\section{References}

1. Haase, P.; Tonkin, J.D.; Stoll, S.; Burkhard, B.; Frenzel, M.; Geijzendorffer, I.R.; Hauser, C.; Klotz, S.; Kuhn, I.; McDowell, W.H.; et al. The next generation of site-based long-term ecological monitoring: Linking essential biodiversity variables and ecosystem integrity. Sci. Total Environ. 2018, 613-614, 1376-1384. [CrossRef] [PubMed]

2. Parmesan, C.; Burrows, M.T.; Duarte, C.M.; Poloczanska, E.S.; Richardson, A.J.; Schoeman, D.S.; Singer, M.C. Beyond climate change attribution in conservation and ecological research. Ecol. Lett. 2013, 16, 58-71. [CrossRef]

3. Magurran, A.E.; Baillie, S.R.; Buckland, S.T.; Dick, J.M.; Elston, D.A.; Scott, E.M.; Smith, R.I.; Somerfield, P.J.; Watt, A.D. Long-term datasets in biodiversity research and monitoring: assessing change in ecological communities through time. Trends Ecol. Evol. 2010, 25, 574-582. [CrossRef] [PubMed]

4. Nager, R.G.; Hafner, H.; Johnson, A.R.; Cézilly, F. Environmental Impacts on Wetland Birds: Long-Term Monitoring Programmes in the Camargue, France. Ardea 2010, 98, 309-318. [CrossRef]

5. Grumbine, R.E. What is ecosystem management? Conserv. Biol. 1994, 8, 27-38. [CrossRef]

6. Lambeck, R.J. Focal species: A multi-species umbrella for nature conservation. Conserv. Biol. 1997, 11, 849-856. [CrossRef]

7. Vos, P.; Meelis, E.; Ter Keurs, W.J. A framework for the design of ecological monitoring programs as a tool for environmental and nature management. Environ. Monit. Assess. 2000, 61, 317-344. [CrossRef]

8. Sutherland, W.J.; Newton, I.; Green, R. Bird Ecology and Conservation: A Handbook of Techniques; Oxford University Press: Oxford, UK, 2004; Volume 1.

9. Ramírez, F.; Rodríguez, C.; Seoane, J.; Figuerola, J.; Bustamante, J. How will climate change affect endangered Mediterranean waterbirds? PLOS ONE 2018, 13, e0192702. [CrossRef]

10. Bako, G.; Tolnai, M.; Takacs, A. Introduction and testing of a monitoring and colony-mapping method for waterbird populations that uses high-speed and ultra-detailed aerial remote sensing. Sensors 2014, 14, 12828-12846. [CrossRef]

11. Frederick, P.C.; Towles, T.; Sawicki, R.J.; Bancroft, G.T. Comparison of aerial and ground techniques for discovery and census of wading bird (Ciconiiformes) nesting colonies. The Condor 1996, 98, 837-841. [CrossRef]

12. Kushlan, J.A. Effects of helicopter censuses on wading bird colonies. J. Wildlife Manage. 1979, 43, 756-760. [CrossRef]

13. Díaz-Delgado, R. An integrated monitoring programme for Doñana Natural Space: The set-up and implementation. In Conservation Monitoring in Freshwater Habitats: A Practical Guide and Case Studies; Hurford, C., Schneider, M., Cowx, I., Eds.; Springer Netherlands: Dordrecht, The Netherlands, 2010; pp. 325-337. 
14. Kingsford, R.T.; Porter, J.L. Monitoring waterbird populations with aerial surveys what have we learnt? Wildl. Res. 2009, 36, 29-40. [CrossRef]

15. Anderson, K.; Gaston, K.J. Lightweight unmanned aerial vehicles will revolutionize spatial ecology. Front. Ecol. Environ. 2013, 11, 138-146. [CrossRef]

16. Sardà-Palomera, F.; Bota, G.; Padilla, N.; Brotons, L.; Sardà, F. Unmanned aircraft systems to unravel spatial and temporal factors affecting dynamics of colony formation and nesting success in birds. J. Avian Biol. 2017, 48, 1273-1280. [CrossRef]

17. Hodgson, J.C.; Baylis, S.M.; Mott, R.; Herrod, A.; Clarke, R.H. Precision wildlife monitoring using unmanned aerial vehicles. Sci. Rep. 2016, 6, 22574. [CrossRef] [PubMed]

18. Brisson-Curadeau, E.; Bird, D.; Burke, C.; Fifield, D.A.; Pace, P.; Sherley, R.B.; Elliott, K.H. Seabird species vary in behavioural response to drone census. Sci. Rep. 2017, 7, 17884. [CrossRef] [PubMed]

19. Han, Y.-G.; Yoo, S.H.; Kwon, O. Possibility of applying unmanned aerial vehicle (UAV) and mapping software for the monitoring of waterbirds and their habitats. J. Ecol. Environ. 2017, 41. [CrossRef]

20. Fuller, A.R.; McChesney, G.J.; Golightly, R.T. Aircraft disturbance to Common Murres (Uria aalge) at a breeding colony in Central California, USA. Waterbirds 2018, 41, 257-267. [CrossRef]

21. Lyons, M.; Brandis, K.; Callaghan, C.; McCann, J.; Mills, C.; Ryall, S.; Kingsford, R. Bird interactions with drones, from individuals to large colonies. Australian Field Ornithol. 2018, 35. [CrossRef]

22. Descamps, S.; Béchet, A.; Descombes, X.; Arnaud, A.; Zerubia, J. An automatic counter for aerial images of aggregations of large birds. Bird Study 2011, 58, 302-308. [CrossRef]

23. Grenzdörffer, G.J. UAS-based automatic bird count of a common gull colony. Int. Arch. Photogramm. Remote Sens. Spat. Inf. Sci. 2013, 1, 169-174. [CrossRef]

24. Díaz-Delgado, R.; Aragonés, D.; Afán, I.; Bustamante, J. Long-term monitoring of the flooding regime and hydroperiod of Doñana marshes with Landsat time series (1974-2014). Remote Sens. 2016, 8. [CrossRef]

25. Haberl, H.; Gaube, V.; Díaz-Delgado, R.; Krauze, K.; Neuner, A.; Peterseil, J.; Plutzar, C.; Singh, S.J.; Vadineanu, A. Towards an integrated model of socioeconomic biodiversity drivers, pressures and impacts. A feasibility study based on three European long-term socio-ecological research platforms. Ecol. Econ. 2009, 68, 1797-1812. [CrossRef]

26. Santoro, S.; Máñez, M.; Green, A.J.; Figuerola, J. Formation and growth of a heronry in a managed wetland in Doñana, southwest Spain. Bird Study 2010, 57, 515-524. [CrossRef]

27. Santoro, S.; Green, A.J.; Speakman, J.R.; Figuerola, J. Facultative and non-facultative sex ratio adjustments in a dimorphic bird species. Oikos 2015, 124, 1215-1224. [CrossRef]

28. Ramo, C.; Aguilera, E.; Figuerola, J.; Máñez, M.; Green, A.J. Long-term population trends of colonial wading birds breeding in Doñana (SW Spain) in relation to environmental and anthropogenic factors. Ardeola 2013, 60, 305-326. [CrossRef]

29. Figuerola, J.; Máñez, M.; Ibáñez, F.; García, L.; Garrido, H. Morito Común, Plegadis falcinellus. In Atlas de las Aves Reproductoras de España; Martí, R., del Moral, J.C., Eds.; Dirección General de Conservación de la Naturaleza-SEO/BirdLife: Madrid, Spain, 2004; pp. 124-125.

30. Máñez, M.; García, L.; Arroyo, J.L.; Del Valle, J.L.; Rodríguez, R.; Martínez, M.; Chico, A. Twenty-two years of monitoring of the Glossy Ibis (Plegadis falcinellus) in Doñana. In Proceedings of the First International Workshop on Glossy Ibis, Doñana, Spain, 27-29 November 2017.

31. BirdLife International. Plegadis falcinellus. The IUCN Red List of Threatened Species. 2016. Available online: http:/ / dx.doi.org/10.2305/IUCN.UK.2016-3.RLTS.T22697422A86436401.en (accessed on 19 November 2018).

32. Madroño, A.; González, G.G.; Atienza, J.C. Libro rojo de las aves de España; Dirección General para la Biodiversidad-SEO/BirdLife: Madrid, Spain, 2004.

33. Del Hoyo, J.; Elliot, A.; Sargatal, J. Handbook of the Birds of the World; Lynx Editions: Barcelona, Spain, 1992.

34. Valverde, J.A. Vertebrados de las marismas del Guadalquivir (introducción al estudio ecológico); Archivos del Instituto de Aclimatación: Almería, Spain, 1960; Vol. IX.

35. Cramp, S.; Simmons, K.E.L.; Perrins, C.M. The Birds of the Western Palearctic; Oxford University Press: Oxford, UK, 1977; Vol. I.

36. Ivosevic, B.; Han, Y.-G.; Kwon, O. Calculating coniferous tree coverage using unmanned aerial vehicle photogrammetry. J. Ecol. Env. 2017, 41. [CrossRef] 
37. Richards, J.A.; Richards, J.A. Remote Sensing Digital Image Analysis; Springer: Berlin/Heidelberg, Germany, 1999; Volume 3.

38. Pal, M. Random forest classifier for remote sensing classification. Int. J. Remote Sens. 2007, 26, $217-222$. [CrossRef]

39. Belgiu, M.; Drăguţ, L. Random forest in remote sensing: A review of applications and future directions. ISPRS J. Photogramm. Remote Sens. 2016, 114, 24-31. [CrossRef]

40. R Core Team. R: A Language and Environment for Statistical Computing; R Foundation for Statistical Computing: Vienna, Austria, 2017; Available online: http: / /www.R-project.org/ (accessed on 22 October 2018).

41. Bivand, R.; Keitt, T.K.; Rowlingson, B. rgdal: Bindings for the 'Geospatial' Data Abstraction Library, R package version 1.2-16; 2018. Available online: https://cran.r-project.org/web/packages/rgdal/index.html (accessed on 22 October 2018).

42. Hijmans, R.J. raster: Geographic Data Analysis and Modeling, R package version 2.6-7; 2017. Available online: https:/ / cran.r-project.org/web/packages/raster/index.html (accessed on 22 October 2018).

43. Kuhn, M.; Wing, J.; Weston, S.; Williams, A.; Keefer, C. caret: Classification and Regression Training, R package version 6.0-80; 2012. Available online: https://cran.r-project.org/web/packages/caret/index.html (accessed on 22 October 2018).

44. Liaw, A.; Wiener, M. Classification and Regression by randomForest. $R$ News 2002, 2, 18-22.

45. Schindelin, J.; Arganda-Carreras, I.; Frise, E.; Kaynig, V.; Longair, M.; Pietzsch, T.; Preibisch, S.; Rueden, C.; Saalfeld, S.; Schmid, B. Fiji: an open-source platform for biological-image analysis. Nat. Meth. 2012, 9, 676. [CrossRef] [PubMed]

46. Rueden, C.T.; Schindelin, J.; Hiner, M.C.; DeZonia, B.E.; Walter, A.E.; Arena, E.T.; Eliceiri, K.W. ImageJ2: ImageJ for the next generation of scientific image data. BMC Bioinform. 2017, 18, 529. [CrossRef] [PubMed]

47. Dulava, S.; Bean, W.T.; Richmond, O.M. Environmental reviews and case studies: Applications of unmanned aircraft systems (UAS) for waterbird surveys. Environ. Pract. 2015, 17, 201-210. [CrossRef]

48. Barr, J.R.; Green, M.C.; DeMaso, S.J.; Hardy, T.B. Detectability and visibility biases associated with using a consumer-grade unmanned aircraft to survey nesting colonial waterbirds. J. Field Ornithol. 2018, 89, $242-257$. [CrossRef]

49. Mallard, F.; Le Bourlot, V.; Tully, T. An automated image analysis system to measure and count organisms in laboratory microcosms. PLOS ONE 2013, 8, e64387. [CrossRef] [PubMed]

50. Trathan, P.N. Image analysis of color aerial photography to estimate penguin population size. Wildlife Soc. B. 2004, 32, 332-343. [CrossRef]

51. Hurford, C. Improving the accuracy of bird counts using manual and automated counts in ImageJ: An open-source image processing program. In The Roles of Remote Sensing in Nature Conservation: A Practical Guide And Case Studies; Díaz-Delgado, R., Lucas, R., Hurford, C., Eds.; Springer International Publishing: Cham, Switzerland, 2017; pp. 249-276. [CrossRef]

52. Chabot, D.; Francis, C.M. Computer-automated bird detection and counts in high-resolution aerial images: A review. J. Field Ornithol. 2016, 87, 343-359. [CrossRef]

53. Liu, C.-C.; Chen, Y.-H.; Wen, H.-L. Supporting the annual international black-faced spoonbill census with a low-cost unmanned aerial vehicle. Ecol. Inform. 2015, 30, 170-178. [CrossRef]

54. Díaz-Delgado, R.; Máñez, M.; Martínez, A.; Canal, D.; Ferrer, M.; Aragonés, D. Using UAVs to map aquatic bird colonies. In The Roles of Remote Sensing in Nature Conservation; Springer: Cham, Switzerland, 2017; pp. 277-291.

55. Linchant, J.; Lisein, J.; Semeki, J.; Lejeune, P.; Vermeulen, C. Are unmanned aircraft systems (UASs) the future of wildlife monitoring? A review of accomplishments and challenges. Mammal. Rev. 2015, 45, $239-252$. [CrossRef]

(C) 2018 by the authors. Licensee MDPI, Basel, Switzerland. This article is an open access article distributed under the terms and conditions of the Creative Commons Attribution (CC BY) license (http:/ / creativecommons.org/licenses/by/4.0/). 